\title{
ANTIFUNGAL ACTIVITY OF A COMPOSITION OF SELENIUM AND IODINE NANOPARTICLES
}

\author{
Anatolii Vasylchenko ${ }^{1}$, Stanislav Derevianko ${ }^{1}$ \\ ${ }^{1}$ Institute of Agricultural Microbiology and Agro-industrial Production of NAAS of Ukraine, 97 Shevchenka St., \\ Chernihiv, 14027, Ukraine
}

Link to this article: https://doi.org/10.11118/actaun.2021.044

Received: 12. 3. 2021, Accepted: 24. 6. 2021

To cite this article: VASYLCHENKO ANATOLII, DEREVIANKO STANISLAV. 2021. Antifungal Activity of a Composition of Selenium and Iodine Nanoparticles. Acta Universitatis Agriculturae et Silviculturae Mendelianae Brunensis, 69(4): 491-500.

\begin{abstract}
The aim of this study was to investigate antifungal properties of the composition of Se and I nanoparticles (NPs) against strains of phytopathogenic fungi Acremonium cucurbitacearum 502, Acremonium strictum 048 and Fusarium sp. 072. It has been found that the composition of Se and I NPs has antifungal properties against these strains. The highest antifungal activity was against strain A. cucurbitacearum 502, manifesting as the decrease in the number of colonies (by 60.00-86.67\%) and the decrease of the diameter of colonies (by 78.95-94.22\%). Antifungal activity against strain A. strictum 048 manifested as the decrease in the diameter of colonies by $52.67-75.00 \%$. The diameter of colonies the strain Fusarium sp. 072 decreased by 25.26-51.75\%. Changes in the morphology of the colonies of the strain A. strictum 048 were also noticed. Thus, the composition of Se and I nanoparticles has antifungal activity against fungal strains A. cucurbitacearum 502, A. strictum 048 and Fusarium sp. 072, which are valuable plant pathogens. The composition of Se and I NPs can be recommended for the development of the measures for the control of phytopathogenic fungi.
\end{abstract}

Keywords: fungi, plant-pathogenic fungi, nanoparticles, antifungal activity, selenium, iodine, acremonium, fusarium

\section{INTRODUCTION}

The search for new antifungal substances and the development of modern antifungal preparations is one the most important tasks of mycology. A high interest in studying the nanoparticles (NPs) and their use in the development of antifungal preparations, especially for the control of the fungal pathogens of crop cultures is noticed recently. Nowadays NPs in various forms are used in human and veterinary medicine, agriculture, perfumery, textile and food industry. Many studies confirm antiviral, antibacterial and antifungal properties of NPs of metals, metal oxides and nonmetals.

Particular attention is paid to the influence of different NPs on fungi. It is known that NPs of metals, metal oxides, nonmetals, polymers and other substances has antifungal activity.
Thus, NPs are perspective for the use in human and veterinary medicine and agriculture as antifungal agents.

For instance, it is known that silver NPs has antifungal activity against broad spectrum of plant-pathogenic fungi: Alternaria alternata, Alternaria brassicicola, Alternaria solani, Botrytis cinerea, Cladosporium cucumerinum, Corynespora cassiicola, Cylindrocarpon destructans, Didymella bryoniae, Fusarium oxysporum f. sp. cucumerinum, Fusarium oxysporum f. sp. lycopersici, Fusarium oxysporum, Fusarium solani, Fusarium sp., Glomerella cingulata, Monosporascus cannoballus, Pythium aphanidermatum, Pythium spinosum and Stemphylium lycopersici (Kim et al., 2012).

Copper NPs show antifungal activity against phytopathogenic fungi Phoma destructiva, Curvularia lunata, Alternaria alternata and Fusarium oxysporum 
(Kanhed et al., 2014). It was found that copper NPs has much higher antifungal activity against fungi Phoma destructiva, Curvularia lunata, Alternaria alternata and Fusarium oxysporum than such commercial preparations as bavistin, suppressing the growth of these fungi at very low concentrations (Kanhed et al., 2014).

Zinc oxide NPs has antifungal activity against phytopathogenic fungi Botrytis cinerea and Penicillium expansum (He et al., 2011).

NPs of molybdenum and cobalt compounds also have high antifungal activity. Thus, molybdenum trioxide NPs have antifungal activity against Candida albicans and Aspergillus niger along with antibacterial and antioxidant activity (Fakhri and Nejad, 2016). Cobalt dithiocarbamate NPs have antifungal activity against Candida albicans, Aspergillus flavus and Aspergillus niger (Nabipour et al., 2011).

Not only NPs of metals and their compounds, but also NPs of nonmetals has high scientific and industrial importance. Thus, surface-modified sulfur NPs have prominent antifungal activity against Aspergillus niger and Fusarium oxysporum reducing their radial growth, spore formation and phospholipid content (Choudhury et al., 2011).

Selenium NPs have antifungal activity against such fungi as Macrophomina phaseolina, Sclerotinia sclerotiorum, Diaporthe longicolla (Vrandečić et al., 2020), Malassezia sympodialis, Malassezia furfur, Aspergillus terreus (Shahverdi et al., 2020), Candida albicans, Aspergillus fumigatus, Aspergillus niger (Shakibaie et al., 2015; Eswarapriya and Jegatheesan, 2015), Pyricularia grisea, Colletotrichum capsici, Alternaria solani (Joshi et al., 2019), Trichophyton rubrum (Yip et al., 2014) and others.

Thus, NPs of such simple substances and chemical compounds as silver, copper, zinc oxide, molybdenum trioxide, cobalt dithiocarbamate, sulfur and selenium have antifungal activity against broad spectrum of fungi, which includes human pathogens as well as pathogens of animals and crop cultures.

Therefore, the aim of our study was to investigate antifungal activity of the composition of Se and I NPs against fungal strains Acremonium cucurbitacearum 502, Acremonium strictum 048 and Fusarium sp. 072, which are dangerous plant pathogens.

\section{MATERIALS AND METHODS}

\section{Object and Subject of the Study}

Object of the study - growth of the cultures of phytopathogenic fungi in vitro under the influence of the composition of Se and I NPs.

Subject of the study - antifungal activity of NPs against phytopathogenic fungi.

\section{Materials of the Study}

Sol of the composition of Se and I NPs, which was obtained by laser ablation (Kosinov and Kaplunenko, 2007), was kindly given to us by the head of "Nanomaterials and nanotechnologies" LTD, doctor of technical sciences, Kaplunenko Volodymyr Heorhiiovych.

Strains of phytopathogenic fungi Acremonium cucurbitacearum 502, Acremonium strictum 048 and Fusarium sp. 072 were kindly given to us by the head of the laboratory of plant-microorganism interactions of the Institute of Agricultural Microbiology and Agro-industrial Production of NAAS of Ukraine (IAMAP NAAS), doctor of biological sciences, professor, Nadkernychna Olena Volodymyrivna and chief researcher of the laboratory of plantmicroorganism interactions of IAMAP NAAS, doctor of biological sciences, senior researcher, Kopylov Yevhenii Pavlovych.

Wort agar, the medium used in the study, was prepared from wort, agar and water. The wort was purchased from Chernihiv beer factory "Desna" (Ukraine) and the agar was purchased from Ferak Berlin GmbH (Germany).

\section{Methods}

Morphology of NPs was studied by transmission electron microscopy on the microscope JEOL JEM1400 (Japan). Diluted sol of NPs was put on copper grids with carbon-formvar coating and dried in the air at room temperature.

Antifungal activity was studied by the addition of NPs to the culture medium, which was further used for fungi cultivation. $4.8 \%$ of sterile sol of the composition of Se and I NPs was added to the molten wort agar $\left(40-50^{\circ} \mathrm{C}\right)$. After the addition of NPs the medium was mixed properly and poured into Petri dishes $\left(15 \mathrm{~cm}^{3}\right)$. Intact wort agar without NPs served as control variant.

After solidification of the medium, it was inoculated with cultures of fungi by means of inoculation needle. There were 5 Petri dishes for each variant of medium (5 repetitions). Each Petri dish was inoculated at 3 locations. Cultures were grown in thermostat at the temperature $25^{\circ} \mathrm{C}$. Diameters of colonies were measured at $2^{\text {nd }}, 3^{\text {rd }}$ and $4^{\text {th }}$ days of cultivation. Antifungal activity was measured by the decrease in the diameter of colonies or absence of fungal growth

Statistical analysis was done in statsoft STATISTICA 10 software using ANOVA analysis. Weighted means (WM) were used to display average values. Duncan's new multiple range test (DMRT) was used to assess significance. 20-30 values (Valid N) were used for the analysis.

\section{RESULTS}

\section{Morphology of NPs}

According to the results of transmission electron microscopy it has been found that the composition of Se and I NPs contains separate triangular, irregular NPs and their aggregates. Triangular NPs have size of the dimension $30 \mathrm{~nm}$. Irregular 
NPs are $10-60 \mathrm{~nm}$ in size. Sizes of aggregates are 150-200 nm (Fig. 1a, b).

\section{Antifungal Activity of NPs}

According to the results of the study, the composition of Se and I NPs decrease the number and the diameter of the colonies of fungal strain Acremonium cucurbitacearum 502 and the diameter of colonies of strains Acremonium strictum 048 and Fusarium sp. 072.

\section{Influence of the Composition of Se and I NPs on the Growth of the Strain Acremonium cucurbitacearum 502}

It has been found that on the $2^{\text {nd }}$ day after inoculation the average number of A. cucurbitacearum 502 colonies on the control medium was 3.00 , whereas on the medium with the composition of Se and I NPs it was $0.40 \pm 0.25$, which is less by $86.67 \%$. On the $3^{\text {rd }}$ day the average number of colonies on the medium with the composition of Se and I NPs was $1.00 \pm 0.32$ (by $6667 \%$ less). On the $4^{\text {th }}$ day the average number of colonies A. cucurbitacearum 502 on the control medium was 3.00, whereas on the medium with the composition of Se and I NPs it was $1.20 \pm 0.37$ (by 60.00\% less) (Tab. I, Fig. 2, Fig. 3).

On the $2^{\text {nd }}$ day the average diameter of A. cucurbitacearum 502 colonies on the medium with the composition of Se and I NPs was less than in control by $94.22 \%$. On the $3^{\text {rd }}$ day the difference was by $83.70 \%$. On the $4^{\text {th }}$ day - by $78.95 \%$ (Tab. II, Fig. 2, Fig. 3).

\section{Influence of the Composition of Se and I NPs on the Growth of the Strain Acremonium strictum 048}

The number of Acremonium strictum 048 colonies on the medium with the composition of Se and I NPs did not differ as compared to control.

However, the diameter of colonies differed significantly. According to the results of the study it was shown that on the $2^{\text {nd }}$ day the average diameter of A. strictum 048 colonies on the medium with the composition of Se and I NPs was less than in control by $75.00 \%$. On the $3^{\text {rd }}$ day the difference was $60.84 \%$, on the $4^{\text {th }}-52.67 \%$ (Tab. III, Fig. 5).

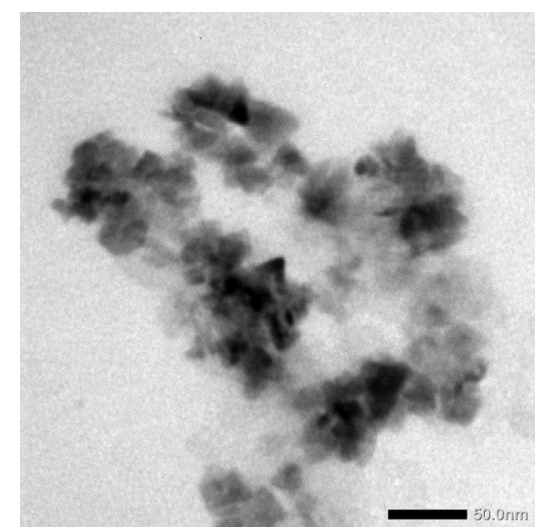

a

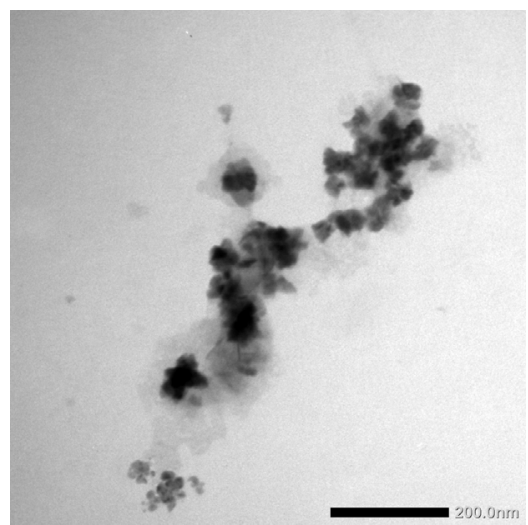

$\mathrm{b}$

1: Electron micrographs of the composition of Se and I NPs. $a, b$-aggregates of Se and I NPS.

I: Influence of the composition of Se and I NPS on the number of colonies of the strain A. cucurbitacearum 502

\begin{tabular}{lcccc}
\hline $\begin{array}{c}\text { Duration } \\
\text { of cultivation }\end{array}$ & $\begin{array}{c}\text { Average number } \\
\text { of colonies (Control) }\end{array}$ & $\begin{array}{c}\text { Average number of colonies } \\
\text { (Se and I NPs) }\end{array}$ & $\begin{array}{c}\text { Difference } \\
\text { with control, \% }\end{array}$ & $\begin{array}{c}\text { Significance, } \\
\text { p (DMRT) }\end{array}$ \\
\hline 2 days & $3.00 \pm 0.00$ & $0.40 \pm 0.25$ & -86.67 & $<0.0003$ \\
3 days & $3.00 \pm 0.00$ & $1.00 \pm 0.32$ & -66.67 & -60.00 \\
4 days & $3.00 \pm 0.00$ & $1.20 \pm 0.37$ & 0.0005 & $<002$ \\
\hline
\end{tabular}

II: Influence of the composition of Se and I NPs on the diameter of A. cucurbitacearum 502 colonies

\begin{tabular}{lcccc}
\hline $\begin{array}{c}\text { Duration } \\
\text { of cultivation }\end{array}$ & $\begin{array}{c}\text { Average diameter } \\
\text { of colonies (Control), cm }\end{array}$ & $\begin{array}{c}\text { Average diameter of colonies } \\
\text { (Se and I NPs), cm }\end{array}$ & $\begin{array}{c}\text { Difference } \\
\text { with control, \% }\end{array}$ & $\begin{array}{c}\text { Significance, } \\
\text { p (DMRT) }\end{array}$ \\
\hline 2 days & $3.75 \pm 0.10$ & $0.22 \pm 0.10$ & -94.22 & $<0.000005$ \\
3 days & $6.57 \pm 0.16$ & $1.10 \pm 0.31$ & -83.70 & -78.95 \\
4 days & $9.50 \pm 0.19$ & $2.00 \pm 0.56$ & $<.00002$ & $<000005$ \\
\hline
\end{tabular}




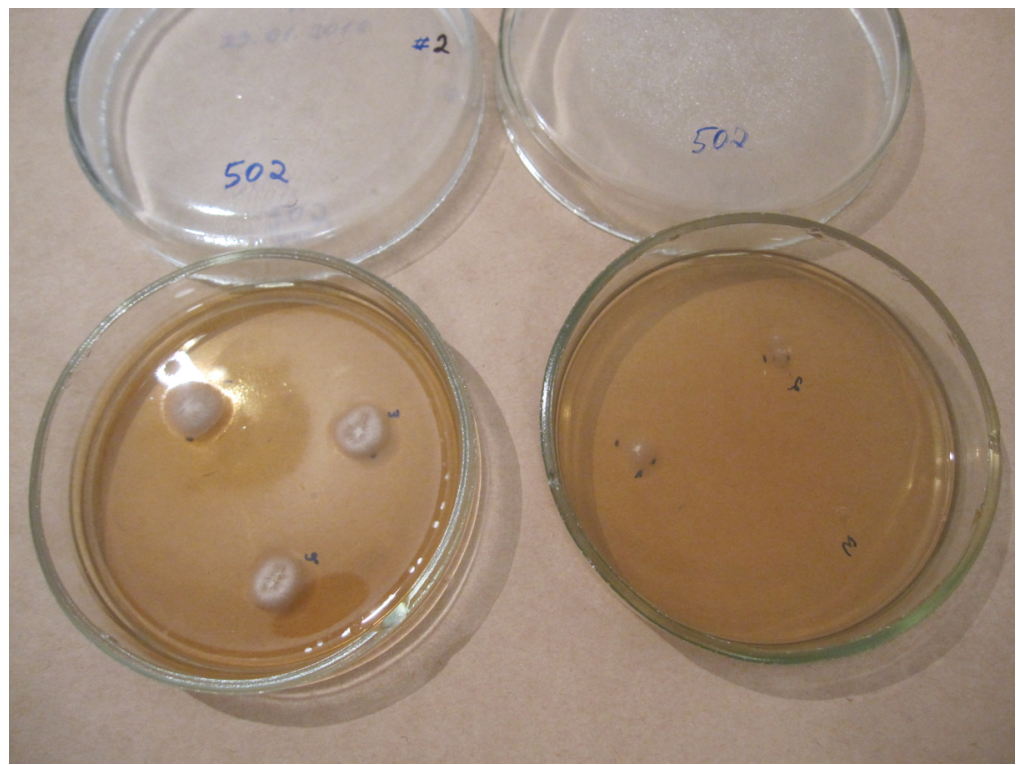

2: Colonies of A. cucurbitacearum 502 in control (left) and on the medium with the composition of Se and I NPs (right). $3^{\text {rd }}$ day of cultivation.



3: Colonies of A. cucurbitacearum 502 in control (left) and on the medium with the composition of Se and I NPs (right). $4^{\text {th }}$ day of cultivation.

III: Influence of the composition of Se and I NPs on the diameter of A. strictum 048 colonies

\begin{tabular}{lcccc}
\hline $\begin{array}{c}\text { Duration } \\
\text { of cultivation }\end{array}$ & $\begin{array}{c}\text { Average diameter } \\
\text { of colonies (Control), cm }\end{array}$ & $\begin{array}{c}\text { Average diameter of colonies } \\
\text { (Se and I NPs), cm }\end{array}$ & $\begin{array}{c}\text { Difference } \\
\text { with control, \% }\end{array}$ & $\begin{array}{c}\text { Significance, } \\
\text { p (DMRT) }\end{array}$ \\
\hline 2 days & $4.60 \pm 0.45$ & $1.15 \pm 0.23$ & -75.00 & $<0.0002$ \\
3 days & $9.92 \pm 0.44$ & $3.88 \pm 0.27$ & -60.84 & $<0.000006$ \\
4 days & $15.95 \pm 0.47$ & $7.55 \pm 0.32$ & -52.67 & $<0.000004$ \\
\hline
\end{tabular}




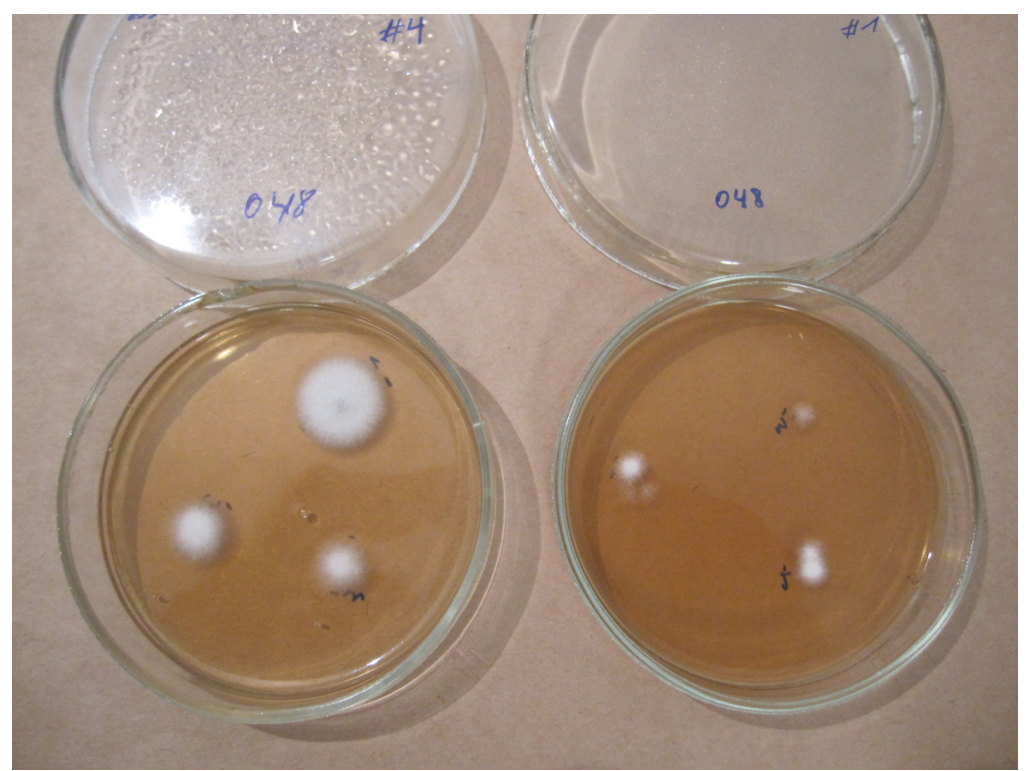

4: Colonies of A. strictum 048 in control(left) and on the medium with the composition of Se and I NPs (right). 3 days after inoculation.

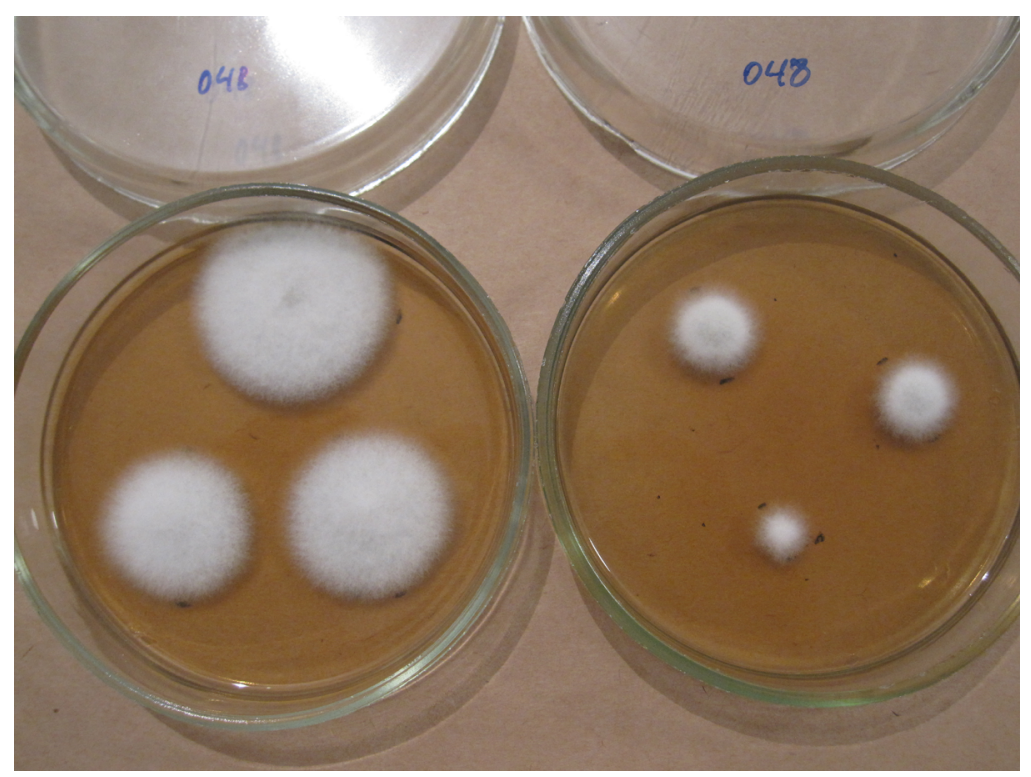

5: Colonies of A. strictum 048 in control (left) and on the medium with the composition of Se and I NPS (right). 4 days after inoculation.

IV: Influence of the composition of Se and I NPs on the diameter of Fusarium sp. 072 colonies

\begin{tabular}{lcccc}
\hline $\begin{array}{c}\text { Duration } \\
\text { of cultivation }\end{array}$ & $\begin{array}{c}\text { Average diameter } \\
\text { of colonies (Control), cm }\end{array}$ & $\begin{array}{c}\text { Average diameter of colonies } \\
\text { (Se and I NPs), cm }\end{array}$ & $\begin{array}{c}\text { Difference } \\
\text { with control, \% }\end{array}$ & $\begin{array}{c}\text { Significance, } \\
\text { p (DMRT) }\end{array}$ \\
\hline 2 days & $9.89 \pm 0.23$ & $4.78 \pm 0.19$ & -51.75 & $<0.000004$ \\
3 days & $16.73 \pm 0.27$ & $11.27 \pm 0.41$ & -32.63 & $<0.000005$ \\
4 days & $22.19 \pm 0.65$ & $16.58 \pm 0.46$ & -25.26 & $<0.000005$ \\
\hline
\end{tabular}




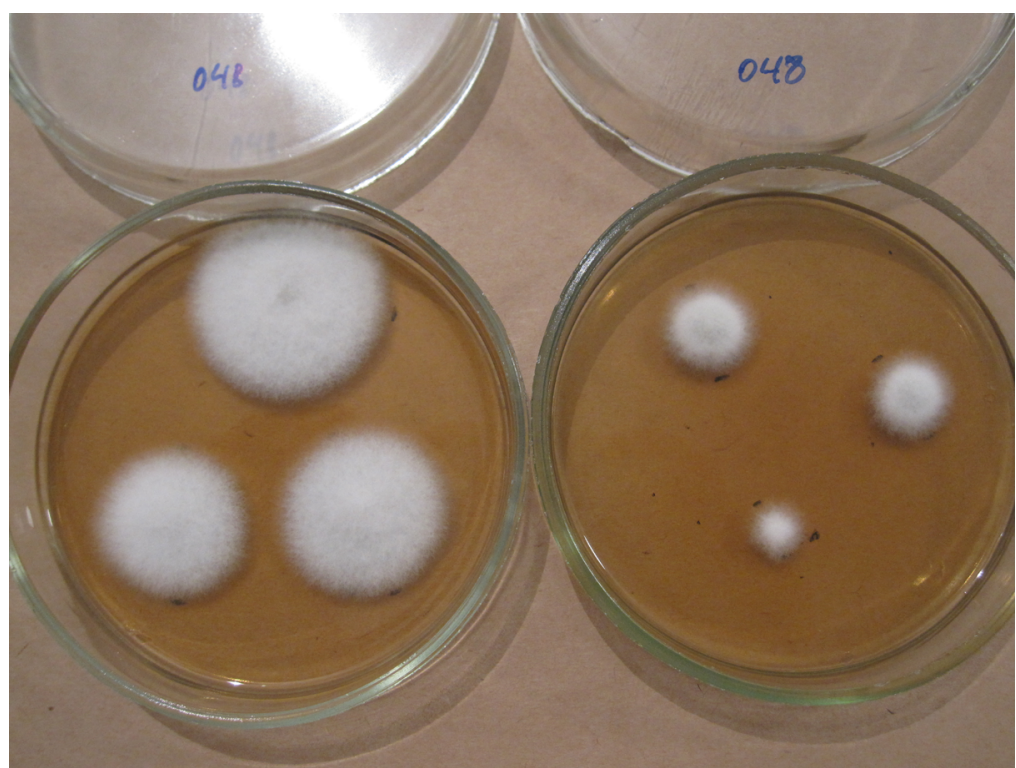

6: Colonies of Fusarium sp. 072 in control (left) and on the medium with the composition of Se and I NPs (right). 3 days after inoculation.

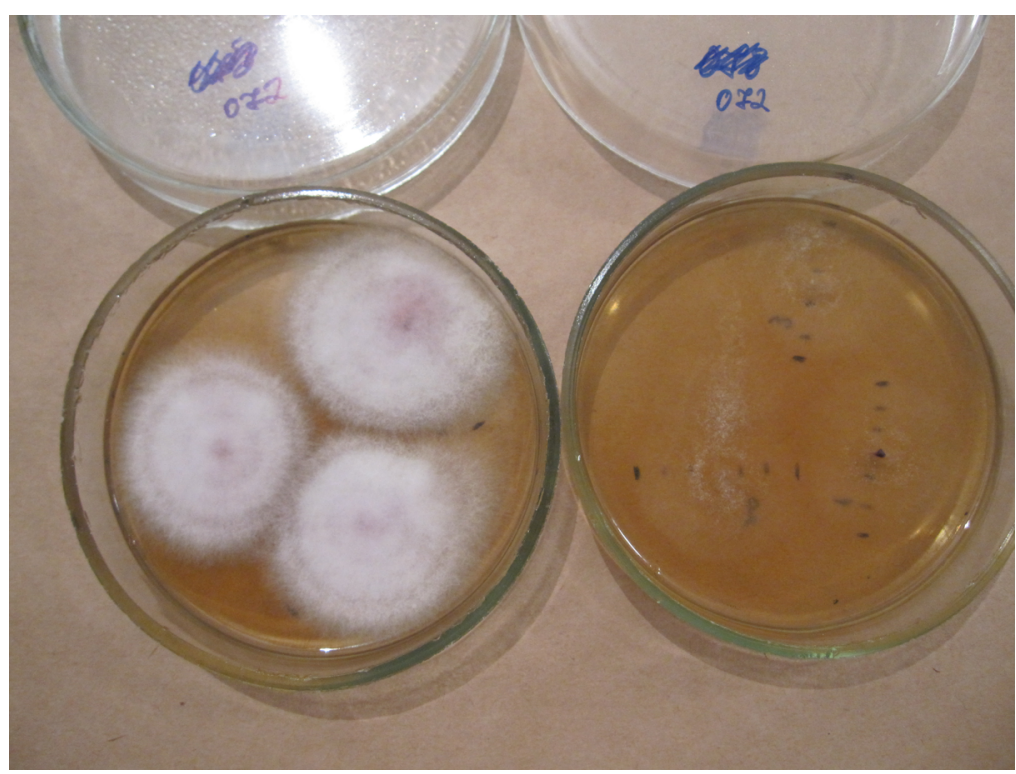

7: Colonies of Fusarium sp. 072 in control (left) and on the medium with the composition of Se and I NPs (right). 4 days after inoculation.

\section{Influence of the Composition of Se and I NPs on the Growth of the Strain Fusarium sp. 072}

The number of the Fusarium sp. 072 colonies on the medium with the composition of Se and I NPs did not differ as compared to control.

However, the diameter of the colonies on the medium with the addition of the composition of Se and I NPs was significantly less than in control. Thus, on the $2^{\text {nd }}$ day the average diameter of the colonies on the medium with the composition of Se and I NPs was less than in control by $51.75 \%$. On the $3^{\text {rd }}$ day the difference was $32.63 \%$, on the $4^{\text {th }}-25.26 \%$ (Tab. IV, Fig. 6, Fig. 7).
Influence of the Composition of Se and I NPs on the Morphology of A. strictum 048 Colonies

Significant difference in morphological properties between A. strictum 048 colonies on the control medium and on the medium with the composition of Se and I NPs were observed (Fig. 8). The formation of the droplets of dark-green and reddish-green exudate by the mycelium was observed on the medium with the composition of Se and I NPs. Also the colonies differed in color and shape. Under the influence of the composition of Se and I NPs colonies of $A$. strictum 048 were prominently umbonate. Dense greenish protuberances were formed at the centres of colonies. Concentric circles of clear dark- 


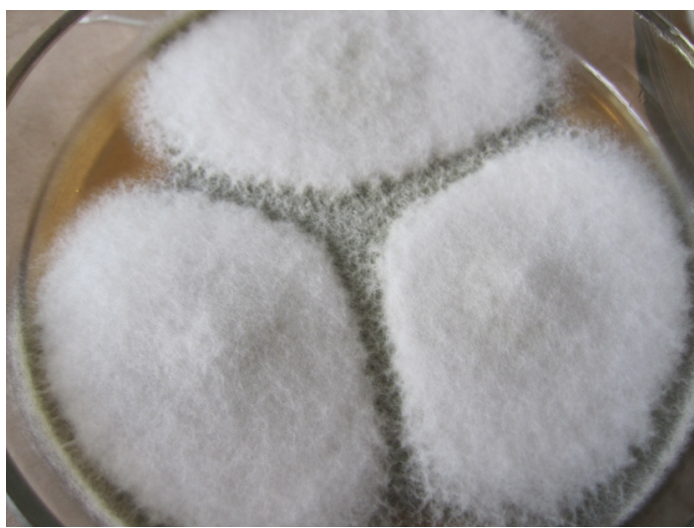

a



$\mathrm{b}$

8: Morphological properties of the A. strictum 048 colonies on the control medium (a) and on the medium with the addition of the composition of Se and I NPs (b). 7 days after inoculation.

green exudate were form around the protuberances (Fig. 8b). Such changes in morphological properties of the colonies can be a result of changes in fungus metabolism, caused by the presence of NPs in culture medium. The influence of the composition of Se and I NPs on the morphology of A. strictum 048 colonies and the metabolism of the fungus deserves further investigation.

Thus, the composition of Se and I NPs affects the strains of plant-pathogenic fungi Acremonium cucurbitacearum 502, Acremonium strictum 048 and Fusarium sp. 072, suppressing their growth and influencing morphological properties.

\section{DISCUSSION}

Thus, the results of our study show that the composition of Se and I NPs inhibits growth of fungal strains Acremonium cucurbitacearum 502, Acremonium strictum 048 and Fusarium sp. 072.

These results agree with results of other authors. It is known that Se NPs have antifungal activity (Vrandečić et al., 2020; Shahverdi et al., 2020; Shakibaie et al., 2015; Eswarapriya and Jegatheesan, 2015; Joshi et al., 2019; Yip et al., 2014). It is also known that soluble compounds of iodine have antifungal activity against such fungi as Venturia inaequalis, Rhizoctonia solani, Fusarium oxysporum, Bipolaris sorokiniana, Fusarium moniliforme (Efimov et al., 2020), Candida albicans, C. parapsilosis, C. glabrata, C. tropicalis, C. lusitaniae, C. guilliermondii, C. krusei (Kondo et al., 2012), Oligoporus placenta, Gloeophyllum trabeum, Coniophora puteana, Trametes versicolor (Ihssen et al., 2014), other fungi and particularly against Acremonium species (Farrag et al., 2012). Thus, the antifungal activity of the composition of Se and I NPs is caused by its components and agrees with existing data.

The mechanisms of antifungal activity of Se NPs are not studied sufficiently. However, they can be understood from the mechanisms of antibacterial activity of Se NPs. Thus, it has been found that quercetin and acetylcholine coated Se NPs significantly increase reactive oxygen species (ROS) production in bacterial cells. And it is supposed that one of the mechanisms of antibacterial activity of Se NPs is associated with ROS production (Huang et al., 2016). Similarly to antibacterial activity, antifungal activity of Se NPs can be caused by ROS production, since high amounts of ROS are dangerous for most living cells. It has been also noticed that Se NPs damage cell membranes of bacterial cells, which can be also a mechanism of antifungal activity (Huang et al., 2016). Moreover, Se NPs can deplete internal ATP and affect membrane potential (Huang et al., 2019).

In studies with Candida glabrata it has been found that Se NPs attach and agglomerate on the surface of cells, cause loss of membrane's smoothness, appearance of bulges and impairment of membrane's integrity (Lotfali et al., 2021). Higher concentrations cause dramatic changes in cell morphology and membranes' breakdown.

It is known that iodine has strong fungicidal, bactericidal and virucidal activity. It is supposed that iodine penetrates cells of microorganisms and interacts with proteins (especially with cysteine and methionine residues), fatty acids and nucleotides, which leads to cell death (McDonnell and Russell, 1999; Springthorpe and Sattar, 1990). Iodine has high affinity to fatty acids, can bind to carboncarbon double bond $(\mathrm{C}=\mathrm{C})$ of unsaturated fats and cause membrane immobilization (Apostolov et al., 1980). In our opinion, similar mechanisms can cause antifungal activity of iodine.

Mechanisms of antifungal activity of the composition of Se and I NPs need further studies in order to obtain the exact data on the mechanisms of the composition's activity.

Thus, our results are consistent with existing data. The composition of Se and I NPs inhibits growth of phytopathogenic fungi significantly, which makes it a promising antifungal material. Nanoparticles has especially high importance today due to several circumstances. For instance, one of the problems 
with conventional fungicides today is fungal resistance to them. A vast number fungi, including plant pathogens, are reported to develop resistance to modern conventional fungicides (McDonald et al., 2019; Yang et al., 2019; Cook et al., 2021; Sevastos et al., 2018).

Also conventional fungicides are shown to be toxic for humans (Lv et al., 2017; Knebel et al., 2019), animals (Gupta et al., 2018; Syromyatnikov et al., 2017; Wade et al., 2019; Kumar et al., 2020; Wu et al., 2018) and plants, including agricultural crops (Shahid et al., 2018; Fedotov et al., 2019).

All these circumstances make NPs, and particularly the composition of Se and I NPs, a promising tool for plant pathogenic fungi control.

\section{CONCLUSION}

It has been found that the composition of Se and I NPs suppresses the growth of the strain Acremonium cucurbitacearum 502 significantly, decreasing both the number (by 60.00-86.67\%) and the diameter of the colonies (by 78.95-94.22\%).

The composition of Se and I NPs suppresses the growth of the strain Acremonium strictum 048, decreasing the diameter of colonies by $52.67-75.00 \%$.

The composition of Se and I NPs suppresses the growth of the strain Fusarium sp. 072, decreasing the diameter of the colonies by $25.26-51.75 \%$.

The composition of Se and I NPs influences the morphology of the colonies of the strain Acremonium strictum 048, causing the appearance of exudate and changes in color.

The composition of Se and I NPs can be recommended for the development measures for the control of plant-pathogenic fungi.

\section{Acknowledgements}

We express our sincere gratitude to the head of "Nanomaterials and nanotechnologies" LTD, doctor of technical sciences, Kaplunenko Volodymyr Heorhiiovych for providing us the composition of Se and I NPs.

We express our sincere gratitude to the transmission electron microscope operator, senior researcher of the Institute of microbiology and virology of NAS of Ukraine, philosophy doctor, Kharchuk Maksym Serhiiovych for electron microscopy study of NPs.

We express our sincere gratitude to the head of the laboratory of plant-microorganism interactions of IAMAP NAAS, doctor of biological sciences, professor, Nadkernychna Olena Volodymyrivna and chief researcher of the laboratory of plant-microorganism interactions of IAMAP NAAS, doctor of biological sciences, senior researcher, Kopylov Yevhenii Pavlovych for providing us strains of plantpathogenic fungi.

We express our sincere gratitude to the senior researcher of the laboratory of plant-microorganism interactions of IAMAP NAAS, candidate of biological sciences, Tsekhmister Hanna Viktorivna for the help in the conduction of the study.

\section{REFERENCES}

APOSTOLOV, K. 1980. The effects of iodine on the biological activities of myxoviruses. Epidemiology \& Infection, 84(3): 381-388.

CHOUDHURY, S. R., GHOSH, M., MANDAL, A., CHAKRAVORTY, D., PAL, M., PRADHAN, S. and GOSWAMI, A. 2011. Surface-modified sulfur nanoparticles: an effective antifungal agent against Aspergillus niger and Fusarium oxysporum. Applied microbiology and biotechnology, 90(2): 733-743.

COOK, N. M., CHNG, S., WOODMAN, T. L., WARREN, R., OLIVER, R. P. and SAUNDERS, D. G. 2021. High frequency of fungicide resistance-associated mutations in the wheat yellow rust pathogen Puccinia striiformis f. sp. tritici. Pest Management Science., 77(7): 3358-3371.

EFIMOV, N. N., LOGINOV, D. A., SHARIPOV, M. Y., NAZAROV, A. A., NELYUBINA, Y. V. and PEREKALIN, D. S. 2020. Unexpected antifungal activity of half-sandwich complexes with metal-iodine bonds. Journal of Organometallic Chemistry, 916: 121272.

ESWARAPRIYA, B. and JEGATHEESAN, K. S. 2015. Antifungal activity of biogenic selenium nanoparticles synthesized from electronic waste. International Journal of PharmTech Research, 8(3): 383-386.

FAKHRI, A. and NEJAD, P. A. 2016. Antimicrobial, antioxidant and cytotoxic effect of Molybdenum trioxide nanoparticles and application of this for degradation of ketamine under different light illumination. Journal of Photochemistry and Photobiology B: Biology, 159: 211-217. 
FARRAG, A. A., ISMAIL, M. A., ABDEL-RAZEK, K. A. and ALI, A. A. 2012. In vitro antifungal effects of some chemotherapeutic agents against fungi commonly isolated from repeat breeder animals. Journal of Basic \& Applied Mycology, 3: 13-19.

FEDOTOV, G. N., SHOBA, S. A., FEDOTOVA, M. F. and GOREPEKIN, I. V. 2019. Assessment of effects of soil allelotoxicity and toxicity of fungicides on the development of grain crops. Eurasian Soil Science, 52(5): 543-549.

GUPTA, P. K. 2018. Veterinary toxicology. Academic Press.

HE, L., LIU, Y., MUSTAPHA, A. and LIN, M. 2011. Antifungal activity of zinc oxide nanoparticles against Botrytis cinerea and Penicillium expansum. Microbiological research, 166(3): 207-215.

HUANG, T., HOLDEN, J. A., HEATH, D. E., O'BRIEN-SIMPSON, N. M. and O'CONNOR, A. J. 2019. Engineering highly effective antimicrobial selenium nanoparticles through control of particle size. Nanoscale, 39(11): 14937-14951.

HUANG, X., CHEN, X., CHEN, Q., YU, Q., SUN, D. and LIU, J. 2016. Investigation of functional selenium nanoparticles as potent antimicrobial agents against superbugs. Acta biomaterialia, 30: 397-407.

IHSSEN, J., SCHUBERT, M., THÖNY-MEYER, L. and RICHTER, M. 2014. Laccase catalyzed synthesis of iodinated phenolic compounds with antifungal activity. PLoS One, 9: e89924.

JOSHI, S. M., DE BRITTO, S., JOGAIAH, S. and ITO, S. I. 2019. Mycogenic selenium nanoparticles as potential new generation broad spectrum antifungal molecules. Biomolecules, 9(9): 419.

KANHED, P., BIRLA, S., GAIKWAD, S., GADE, A., SEABRA, A. B., RUBILAR, O., DURAN, N. and MAHENDRA, R. 2014. In vitro antifungal efficacy of copper nanoparticles against selected crop pathogenic fungi. Materials Letters, 115: 13-17.

KIM, S. W., JUNG, J. H., LAMSAL, K., KIM, S. Y., MIN, J. S. and LEE, Y. S. 2012. Antifungal effects of silver nanoparticles (AgNPs) against various plant pathogenic fungi. Mycobiology, 40(1): 53-58.

KNEBEL, C., HEISE, T., ZANGER, U. M., LAMPEN, A., MARX-STOELTING, P. and BRAEUNING, A. 2019. The azole fungicide tebuconazole affects human CYP1A1 and CYP1A2 expression by an aryl hydrocarbon receptor-dependent pathway. Food and Chemical Toxicology, 123: 481-491.

KONDO, S., TABE, Y., YAMADA, T., MISAWA, S., OGURI, T., OHSAKA, A. and MIIDA, T. 2012. Comparison of antifungal activities of gentian violet and povidone-iodine against clinical isolates of Candida species and other yeasts: a framework to establish topical disinfectant activities. Mycopathologia, 173(1): 21-25.

KOSINOV, M. V. and KAPLUNENKO, V. G. 2007. Method of erosion-explosive dispersion of metals [in Ukrainian: Спосіб ерозійно-вибухового диспергування металів]. Patent of Ukraine No. 23550. State Enterprise Ukrainian Intellectual Property Institute (UKRPATENT).

KUMAR, N., WILLIS, A., SATBHAI, K., RAMALINGAM, L., SCHMITT, C., MOUSTAID-MOUSSA, N. and CRAGO, J. 2020. Developmental toxicity in embryo-larval zebrafish (Danio rerio) exposed to strobilurin fungicides (azoxystrobin and pyraclostrobin). Chemosphere, 241: 124980.

LOTFALI, E., TOREYHI, H., SHARABIANI, K. M., FATTAHI, A., SOHEILI, A., GHASEMI, R., KEYMARAM, M., REZAEE, Y. and IRANPANAH, S. 2021. Comparison of Antifungal Properties of Gold, Silver, and Selenium Nanoparticles Against Amphotericin B-Resistant Candida glabrata Clinical Isolates. Avicenna Journal of Medical Biotechnology, 13(1): 47-50.

LV, X., PAN, L., WANG, J., LU, L., YAN, W., ZHU, Y., XU, Y., GUO, M., ZHUANG, S. 2017. Effects of triazole fungicides on androgenic disruption and CYP3A4 enzyme activity. Environmental pollution, 222: 504-512.

MCDONALD, M. C., RENKIN, M., SPACKMAN, M., ORCHARD, B., CROLL, D., SOLOMON, P. S. and MILGATE, A. 2019. Rapid parallel evolution of azole fungicide resistance in Australian populations of the wheat pathogen Zymoseptoria tritici. Applied and Environmental Microbiology, 85(4): e0190818.

MCDONNELL, G. and RUSSELL, A. D. 1999. Antiseptics and disinfectants: activity, action, and resistance. Clinical microbiology reviews, 12(1): 147-179.

NABIPOUR, H., GHAMMAMY, S. and RAHMANI, A. 2011. Synthesis of a new dithiocarbamate cobalt complex and its nanoparticles with the study of their biological properties. IET Micro \& Nano Letters, 6(4): 217-220.

SEVASTOS, A., KALAMPOKIS, I. F., PANAGIOTOPOULOU, A., PELECANOU, M., ALIFERIS, K. A. 2018. Implication of Fusarium graminearum primary metabolism in its resistance to benzimidazole fungicides as revealed by 1H NMR metabolomics. Pesticide biochemistry and physiology, 148: 50-61.

SHAHID, M., AHMED, B., ZAIDI, A. and KHAN, M. S. 2018. Toxicity of fungicides to Pisum sativum: a study of oxidative damage, growth suppression, cellular death and morpho-anatomical changes. RSC advances, 8(67): 38483-38498.

SHAHVERDI, A. R., FAKHIMI, A., MOSAVAT, G., JAFARI-FESHARAKI, P., REZAIE, S. and REZAYAT, S. M. 2010. Antifungal activity of biogenic selenium nanoparticles. World Applied Sciences Journal, 10(8): 918-922. 
SHAKIBAIE, M., MOHAZAB, N. S. and MOUSAVI, S. A. A. 2015. Antifungal activity of selenium nanoparticles synthesized by Bacillus species Msh-1 against Aspergillus fumigatus and Candida albicans. Jundishapur journal of microbiology, 8(9): e26381.

SPRINGTHORPE, V. S. and SATTAR, S. A. 1990. Chemical disinfection of virus-contaminated surfaces Critical Reviews in Environmental Science and Technology, 20(3): 169-229.

SYROMYATNIKOV, M. Y., KOKINA, A. V., LOPATIN, A. V., STARKOV, A. A. and POPOV, V. N. 2017. Evaluation of the toxicity of fungicides to flight muscle mitochondria of bumblebee (Bombus terrestris L.). Pesticide biochemistry and physiology, 135: 41-46.

VRANDEČIĆ, K., ĆOSIĆ, J., ILIĆ, J., RAVNJAK, B., SELMANI, A., GALIĆ, E., PEM, B., BARBIR, R., VRČEK, I. V. and VINKOVIĆ, T. 2020. Antifungal activities of silver and selenium nanoparticles stabilized with different surface coating agents. Pest Management Science, 76(6): 2021-2029.

WADE, A., LIN, C. H., KURKUL, C., REGAN, E. R. and JOHNSON, R. M. 2019. Combined toxicity of insecticides and fungicides applied to California almond orchards to honey bee larvae and adults. Insects, 10(1): 20.

WU, S., LEI, L., LIU, M., SONG, Y., LU, S., LI, D., SHI, H., RALEY-SUSMAN, K. M. and HE, D. 2018. Single and mixture toxicity of strobilurin and SDHI fungicides to Xenopus tropicalis embryos. Ecotoxicology and environmental safety, 153: 8-15.

YANG, L. N., HE, M. H., OUYANG, H. B., ZHU, W., PAN, Z. C., SUI, Q. J., SHANG, L. P. and ZHAN, J. 2019. Cross-resistance of the pathogenic fungus Alternaria alternata to fungicides with different modes of action. BMC microbiology, 19: 205.

YIP, J., LIU, L., WONG, K. H., LEUNG, P. H., YUEN, C. W. M. and CHEUNG, M. C. 2014. Investigation of antifungal and antibacterial effects of fabric padded with highly stable selenium nanoparticles. Journal of applied polymer science, 131(17): 40728.

Contact information

Anatolii Vasylchenko: top.leader.number.1@gmail.com (corresponding author) Stanislav Derevianko: biopreparat@i.ua 